\title{
Backstep scanning ion conductance microscopy as a tool for long term investigation of single living cells Patrick Happel $^{* 1,2}$ and Irmgard D Dietzel ${ }^{1}$
}

\author{
Address: ${ }^{1}$ Department of Molecular Neurobiochemistry, Ruhr-University Bochum, D-44870 Bochum, Germany and ${ }^{2}$ Central Unit for Ion Beams \\ and Radionuclides (RUBION), Ruhr-University Bochum, D-44870 Bochum, Germany \\ Email: Patrick Happel* - patrick.happel@rub.de; Irmgard D Dietzel - irmgard.d.dietzel-meyer@rub.de \\ * Corresponding author \\ Published: 27 October 2009 \\ Journal of Nanobiotechnology 2009, 7:7 doi:10.1186/1477-3155-7-7 \\ This article is available from: http://www.jnanobiotechnology.com/content/7/I/7 \\ (c) 2009 Happel and Dietzel; licensee BioMed Central Ltd. \\ This is an Open Access article distributed under the terms of the Creative Commons Attribution License (http://creativecommons.org/licenses/by/2.0), \\ which permits unrestricted use, distribution, and reproduction in any medium, provided the original work is properly cited. \\ d: 19 August 2009 \\ Accepted: 27 October 2009
}

\begin{abstract}
Scanning ion conductance microscopy (SICM) is a suitable tool for imaging surfaces of living cells in a contact-free manner. We have shown previously that SICM in backstep mode allows one to trace the outlines of entire cell somata and to detect changes in cellular shape and volume. Here we report that SICM can be employed to quantitatively observe cellular structures such as cell processes of living cells as well as cell somata of motile cells in the range of hours.
\end{abstract}

\section{Findings}

In order to obtain quantitative information about the dynamics of topographic changes as occur during cell migration, long term recordings of living cells are required. While the trajectories of cells can be followed with light microscopy, more complex topographic details of changes in shape can be obtained using scanning probe techniques. For example, atomic force microscopy (AFM) [1] has succesfully been used to observe patches of the cell membrane of living monkey kidney cells for hours as well as to reveal changes and detailed information about the structure of the growth cone of living hippocampal neurons [2-4]. Such applications require repeated scanning over the range of hours. Using this technique, however, the small physical force exerted leads to a visualization of the cytoskeleton rather than the membrane contours when imaging the cell somata [3]. Furthermore, repeated scanning of the membrane may lead to damage or contamination of the probe due to the adhesive forces between tip and glycoproteins [5].

SICM is essentially a contact-free scanning technique which uses electrical resistance changes to detect the dis- tance between the scanning tip and an insulator [6]. The first successful scans of living cell surfaces with this method have been reported on cultured melanocytes and human colon cancer cells using a constant distance operating mode [7]. The observation of microvillar dynamics over the range of ten minutes [8] as well as recordings of cell somata within a confluent cell layer over $24 \mathrm{~h}$ [9] have been demonstrated using SICM. In order to obtain stable recordings from steep and overhanging membranes of non-confluent, single cultured neural cells we have introduced the pulse-mode SICM with floating backstep operation mode to image the topography of single cell bodies of neural cells and thus to monitor single cell shape and volume [10-12]. Recent investigations confirmed the necessity to operate SICM in backstep-type modes if images from entire cells with steep slopes are required and showed that the technique can be extended to a lateral resolution of $50 \mathrm{~nm}$ [13]. However, the actual resolution of SICM images is still a matter of debate [14]. Backstep SICM has also been applied recently to investigate and guide growth cones of leech neurons [15]. To our knowledge the application of SICM to obtain long term recordings of moving entire living cell somata in the range of 
hours has not yet been shown. Here we show examples of the application of backstep SICM to investigate changes in the shape of a terminal part of a nerve cell process and of two contact-forming cells as well as of recordings of the trajectories of a moving oligodendrocyte precursor cell (OPC) for several hours.

\section{Preparation and cell culture}

Neural cells were obtained and cultured as described in [16] (protocol for mixed cultures) with the exception of using a cell density of $50 \times 10^{3}-100 \times 10^{3}$ cells per $\mathrm{cm}^{2}$. Oligodendrocyte precursor cells were obtained and cultured as previously described in [17] but instead of changing the medium to proliferation/differentiation medium cells were continuously kept in a mixture of DMEM/ Ham's F12 (1:1) supplemented with 10\% fetal calf serum.

\section{SICM measurements}

SICM measurements were performed using the pulsemode SICM previously described [10] operating in floating backstep mode [11]. Briefly summarized, current pulses of predefined height were applied and the required voltage measured. The pulse height measured far away from the sample surface was used to define the basal resistance. Then, the probe was approached towards an insulating surface until the resistance exceeded a predefined threshold. A resistance increase of 3\% with respect to the basal resistance was used in the present experiments to stop the approach. The $x, y, z$-coordinates of this point were stored for later reconstruction of the sample surface topography from successively measured points of equal resistance changes. To reduce scanning time the distance that the probe was dragged back was adjusted corresponding to the differences in height detected in a preceeding low resolution prescan. Scanning probes, filled with bath saline (containing in $\mathrm{mM}$ : $\mathrm{NaCl} 110, \mathrm{KCl} 5.4, \mathrm{CaCl}_{2} 1.8$, $\mathrm{MgCl}_{2} 0.8$, Glucose 10, HEPES 10), had an inner diameter of about $1 \mu \mathrm{m}$ and an access resistance of about $4 \mathrm{M} \Omega$. The scans were performed in $3.5 \mathrm{~cm}$ plastic petri dishes coated with poly-L-Lysin in Leibovitz-15 medium. Data were processed using Matlab and ImageJ software.

\section{Long term observation of the terminal part of a nerve cell process}

The terminal part of a nerve cell process of a rat hippocampal neuron was imaged eleven times in 520 minutes [see Additional File 1]. Images are shown unfiltered but interpolated by cubic splines in Figure 1. Images were obtained with a lateral step size of $500 \mathrm{~nm}$ and a vertical step size of $100 \mathrm{~nm}$, acquisition time was about $20 \mathrm{~min}$ utes per frame. In the course of the scanning period the neurite moved towards $y=0 \mu \mathrm{m}$ merging with the structure marked by the yellow arrows in Fig. 1A. The lamellipodium is visible as the delta-formed structure at the end of the neurite (right hand side of the images). Various membrane changes are visible due to appearing and disappearing filopodia (marked by the red arrows in Fig. 1) the height of which appeared from $150 \mathrm{~nm}$ to $300 \mathrm{~nm}$ (see [14] for the restrictions of height detection via SICM of small objects). Figure 2 shows the topographic changes over time in more detail. Fig. 2Ba depicts the height profile along the orange line drawn in Fig. 2A (marked with a) from the frames $\mathrm{A}$ (solid line, $0 \mathrm{~min}$ ), $\mathrm{J}$ (dashed line, $469 \mathrm{~min}$ ) and $\mathrm{K}$ (dotted line, $520 \mathrm{~min}$ ) from Fig. 1. Since overall height increased in scan $\mathrm{K}$ the height profiles of frames A and J are easier to compare. The position of the neurite shifted towards negative $y$-direction whereas its width nearly remained constant (about $6 \mu \mathrm{m}$ ). The process located left of the neurite in A (marked by the white arrow in Fig. 2A) gradually merged with the neurite, completely disappeared in frame F (Fig. 1) and thus is undetectable in the height profiles of scans J and $\mathrm{K}$.

The height profile detected along the orange line marked as b in Fig. 2A is depicted in Fig. 2Bb. Profiles corresponding to increasing scanning time are displayed in the successive traces from bottom to top. In contrast to the profiles depicted in Fig. 2Ba the neurite only shifted slightly towards negative $y$-direction at this position. On the other hand it widened (from about $6 \mu \mathrm{m}$ to about 9 $\mu \mathrm{m})$ and flattened a bit, which could have been due to a slight retraction of the lamellipodium. This becomes visible in the difference image shown in Fig. $2 \mathrm{C}$ which has been created from the subtraction of frame A from frame J (Fig. 1). Here green areas denote areas without any changes in height, red areas correspond to areas of increasing height and blue areas represent areas of decreasing height. Whereas the position of the neurite had clearly shifted towards the negative $y$-direction (large parallel dark blue and dark red areas) the position of the lamellipodium changed only slightly. The slight retraction is visible in the inset in which contrast has been increased (indicated by the small color scale bar shown in the upper left of Fig. 2C) and by the light red and orange area indicated by the white arrow. This indicates that the observed movement occurred not due to drifts in the image frame that would either result in a similar shift of the lamellipodium or, if the image frame drift was circular, result in an angular instead of a parallel dislocation of the neurite.

\section{Long term observation of two neural cells establishing a new cell-cell contact}

Figure 3 shows three dimensional plots of the data interpolated by cubic splines of six successive scans of a cultured neural cell obtained within $202 \mathrm{~min}$. Lateral step size was $500 \mathrm{~nm}$, vertical step size was $100 \mathrm{~nm}$, acquisition time was about 30 min per frame. A movie composed of the top views of the data is available [see Additional File 2]. The red arrow in Fig. 3A marks the most prominent process of the observed cell, the blue and green arrows 

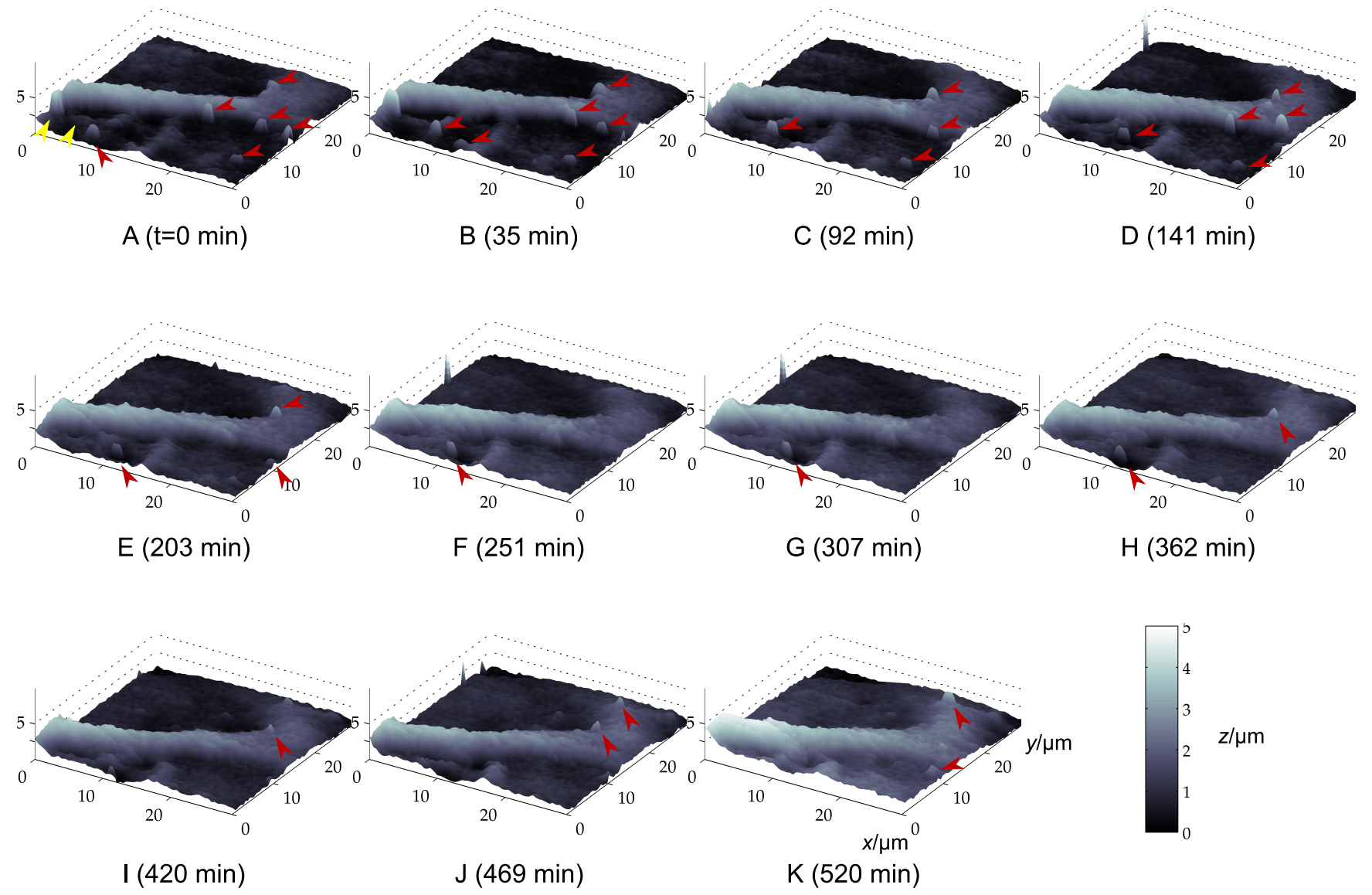

Figure I

Long term observation of the terminal part of a nerve cell process. Eleven successive scans of the terminal part of a nerve cell process performed within $\mathbf{5 2 0}$ minutes. Axes scales represent micrometers as denoted in (K). Yellow arrows in (A) indicate a structure that gradually merges with the neurite. The lamellipodium is clearly visible on the right hand side of each image as well as various filopodia sticking out of the neurite (marked by the red arrows). Scanning step sizes were $500 \mathrm{~nm}$ and $100 \mathrm{~nm}$ in lateral and vertical direction, respectively.

mark two processes most likely originating from a cell outside the scan area. The yellow arrow marks a fan formed structure at the terminal part of the process marked by the green arrow. The structure becomes more apparent in the magnification with increased contrast (inset). The orange arrow marks a small cell extension speculatively in contact with the previously mentioned fan-formed structure. During the $43 \mathrm{~min}$ interval between the first two scans (Fig. 3B) the position of the extension putatively forming the connection between the observed cell and the cell located outside the scan area in the first image (marked by the orange arrow) has either moved towards the upper process (blue arrow) as indicated by the upper orange arrow in Fig. 3B or shifted downwards (lower orange arrow). The fan-formed structure (yellow arrow) and the lower cell extension marked by the lower orange arrow established a new contact as visible in the magnification with higher contrast (inset). The processes marked by the blue and green arrow seem to converge in a branch that becomes visible in the upper right of the image. Also note the change in shape of the prominent cell process (red arrow).

Further 41 min later (Fig. 3C) the cell shape had changed considerably. The major process of the observed cell (marked by the red arrow) underwent a severe reduction in size whereas the protrusion forming the putative cellcell contact had grown towards its target (orange arrow). The former fan-shaped sturcture is no longer visible. The detailed structure of the most likely overlapping membranes remained unresolved. However, a novel membrane protrusion originated from this structure (white arrow) and a novel process developed (cyan arrow). One might also interpret this process as the old major process marked by the red arrow in the previous images. At the same time the putative target cell had moved closer 


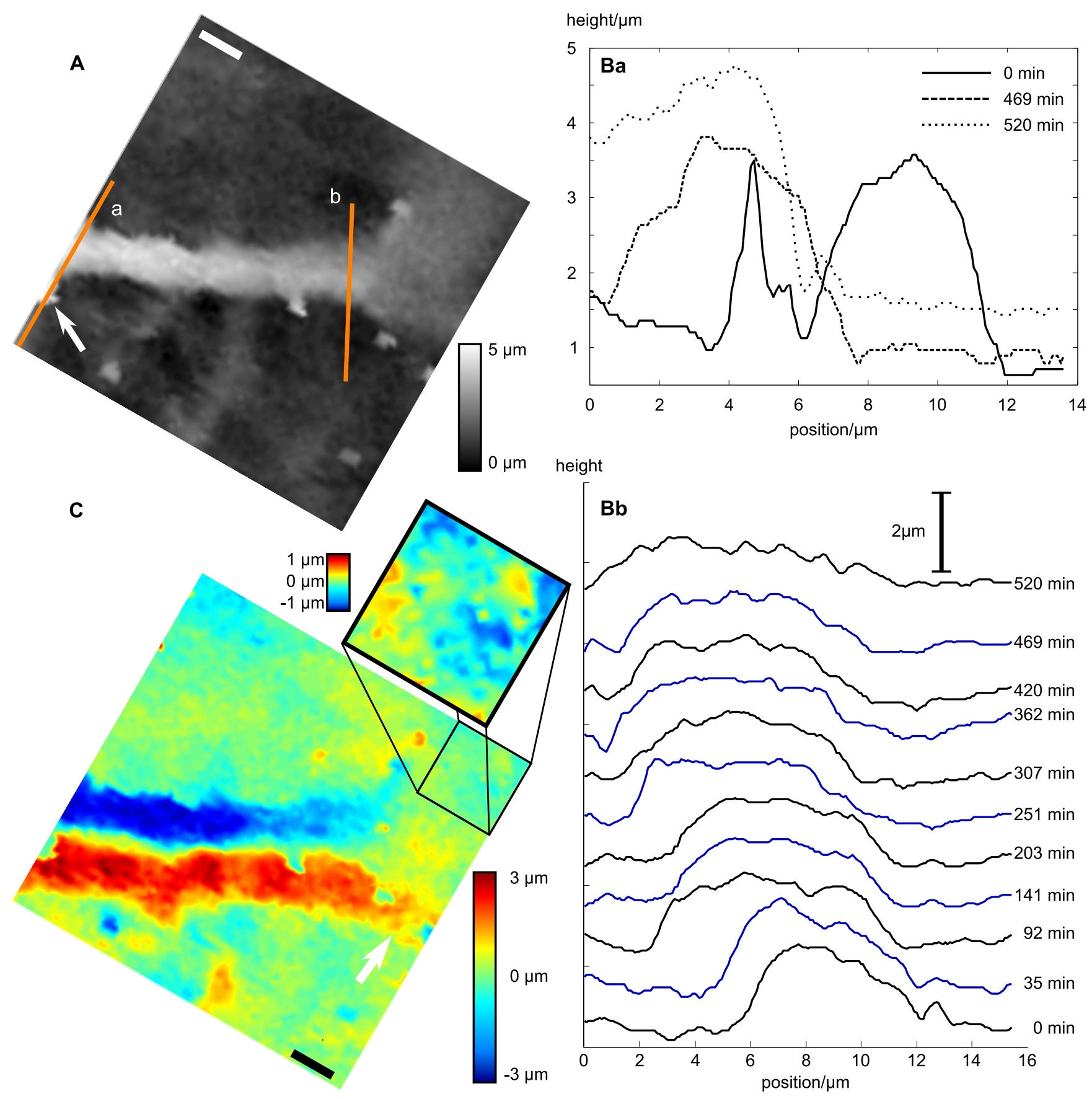

\section{Figure 2}

Analysis of the topographical changes of the neurite shown in Fig. I. (A) Top view of the first scan of the terminal part of the nerve cell process (see Fig. I A). Orange lines indicate the positions of the height profiles shown in (B). (C) Difference image between frame $A$ and J from Fig. I. Lateral scale bars in (A) and (C) represent $3 \mu \mathrm{m}$. The color bar on the right indicates calibration of the $z$-axis in the large image, small color scale corresponds to the inset. Red and blue areas denote inand decreases of height with time, respectively. Inset shows magnified lamellipodium with increased contrast. 


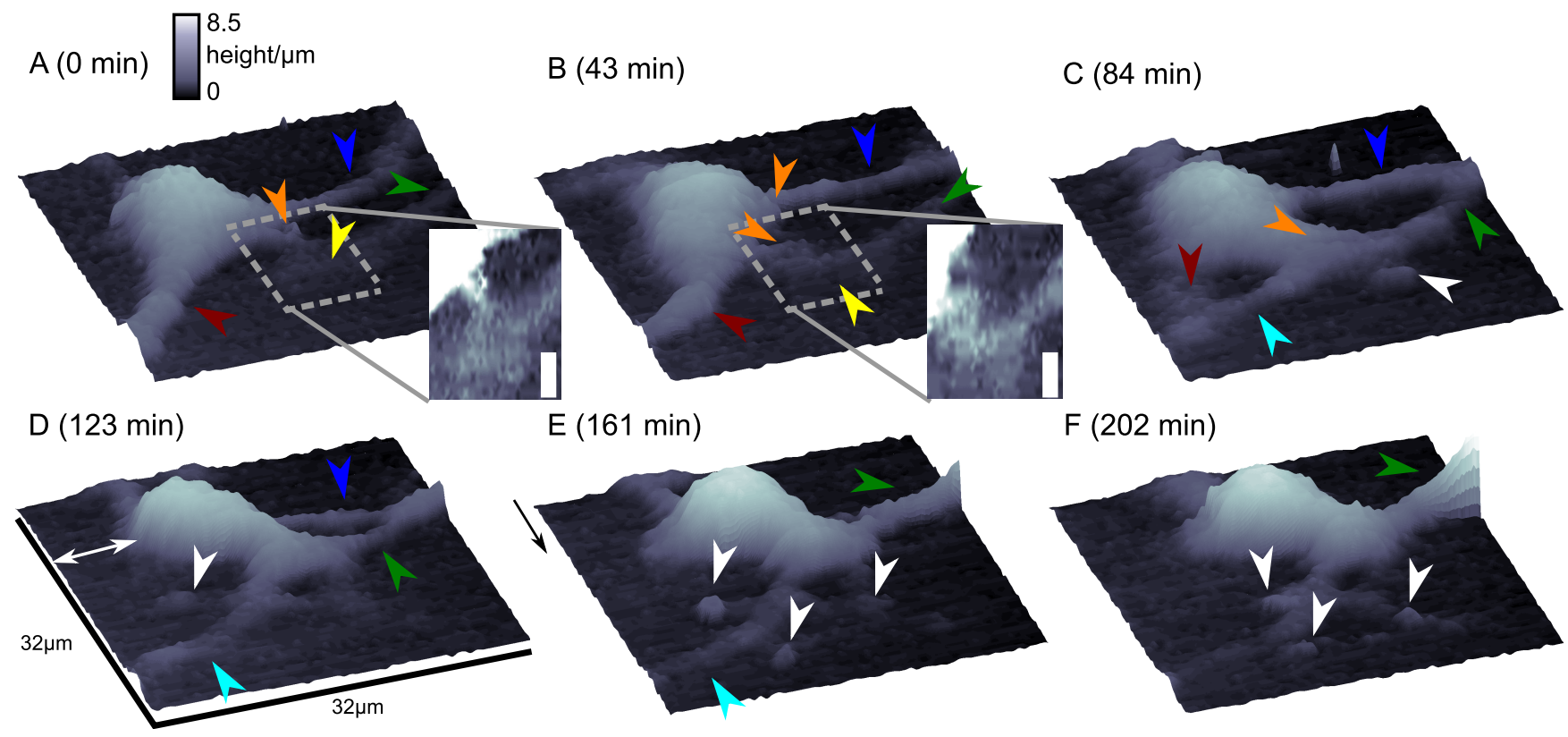

Figure 3

Repeated observation of a cell from a mixed neural-glial culture. Six scans of a cultured neural cell performed within $202 \mathrm{~min}$. (A)-(F) Three dimensional plots of the data. Scan dimensions are indicated in (D), height indicated by the color gradient at the top of frame $(A)$, main scanning direction is indicated by the arrow at the upper left corner in $(E)$. Insets in $(A)$ and (B) display a magnification of the area marked by the dashes with increased contrast, white scale bar indicates $3.5 \mu$ m. Arrows mark different cell parts that changed during the time of observation. Red: Old main process of the observed cell, orange: new leading process, blue and green: upper and lower process of the $2^{\text {nd }}$ cell, respectively, yellow: terminal fan-formed structure of the process marked green, cyan: novel process, white: newly emerging membrane protrusions. White double-headed arrow in (D) marks a change in position of the cell body. Lateral step size was $500 \mathrm{~nm}$, vertical step size was $100 \mathrm{~nm}$, frame acquisition time was about $30 \mathrm{~min}$.

towards the cell in the scanning frame such that the root of the two branches (blue and green arrows) now was located in the scan area. In the fourth scan obtained (Fig. 3D) the position of the cell body had changed (white double headed arrow) and the root of the branch formed by the two processes (marked green and blue) had further shifted into the scan area. Note the novel cell protrusion marked by the white arrow and that the upper process of the branch (marked blue) had become less prominent.

At $t=161 \mathrm{~min}$ and $202 \mathrm{~min}$ the formerly large process (marked blue in the previous images) entirely vanished and a leading single process had established (green arrow). White arrows indicate unambigiously new membrane extensions indicating that the present scanning conditions do not impede process outgrowth. The structures resemble the filopodia of the neurite shown in Fig. 1 and thus could indicate that the ingrowing cell might have been a neuron.

This observation clearly demonstrates that SICM in the present configuration is able to observe spontaneously developing cell rearrangements. Because of the complex rearrangement that occured, the observed changes in the shape of cultured neural cells are most likely not induced by contacts between scanning probe and cell membrane. Both cells move in opposite directions and many membrane protrusions occur in a non-systematic manner. This supports the interpretation that the observed displacement of the neurite shown in Fig. 1 is not artificial due to probe-cell interactions as observed in SICM measurements using slightly different configurations [15].

\section{Observation of a migrating oligodendrocyte precursor cell} Six successive images from a rat oligodendrocyte precursor cell were obtained within 75 minutes using a lateral step size of $1 \mu \mathrm{m}$ and a vertical step size of $100 \mathrm{~nm}$ [see Additional File 3]. Acquisition time was about 10 minutes per frame. The basal plane was noise filtered using a threshold filter setting every $z$-value below $1 \mu \mathrm{m}$ to zero. Data is shown interpolated by cubic splines in Fig. 4.

The entire cell body moved towards the $x$ - and $y$-direction (right hand side of the images) during the time of obser- 

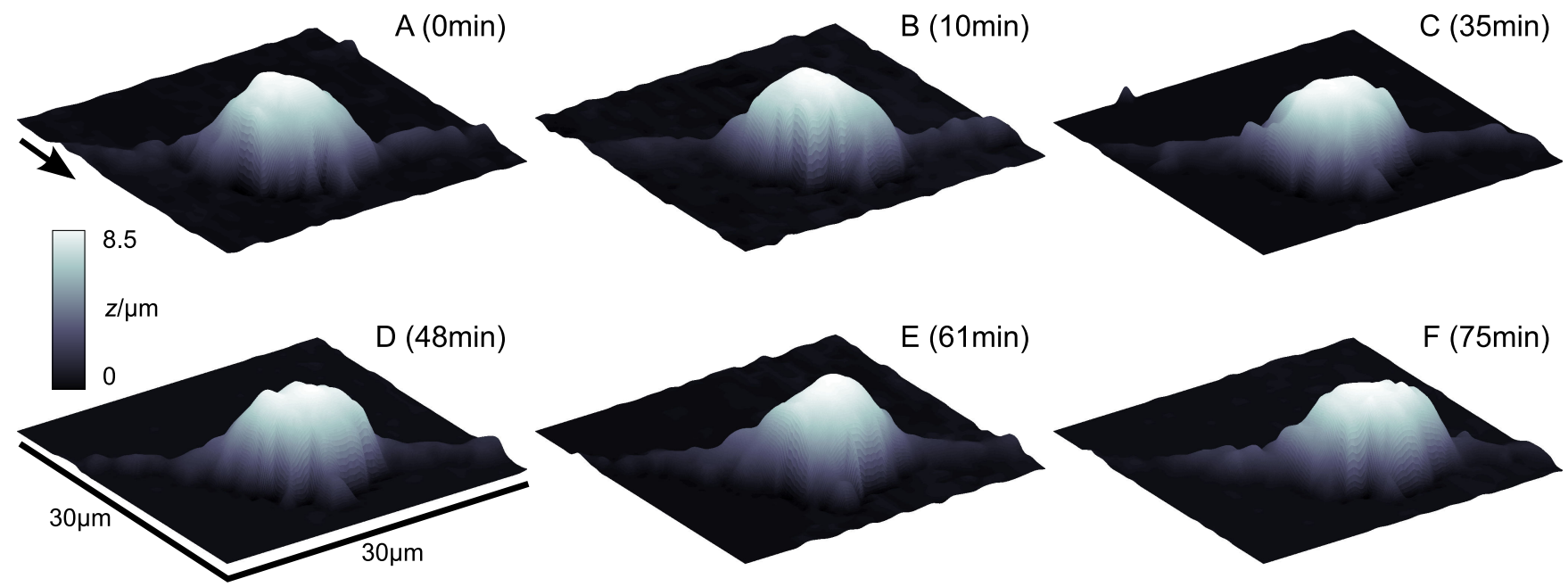

Figure 4

Repeated observation of an oligodendrocyte precursor cell. Six scans of an oligodendrocyte precursor cell recorded within $75 \mathrm{~min}$. (A)-(F) Three-dimensional plots of the data. Scan dimensions are indicated in (D), main scanning direction is indicated by the arrow in (A). Note movement of the cell body into $x$ - and $y$-direction (right hand side of the images). Step sizes were I $\mu \mathrm{m}$ in lateral and $100 \mathrm{~nm}$ in vertical direction.

vation. Clearly visible are the deformations of the cell shape, particularly of the upper part of the cell body occuring during migration. Whereas the cell height in scans A $(8.3 \mu \mathrm{m}), \mathrm{B}(8.2 \mu \mathrm{m}), \mathrm{D}(8.2 \mu \mathrm{m})$ and $\mathrm{F}(8.2 \mu \mathrm{m})$ remained nearly constant it was considerably flatter in scan $\mathrm{C}(8.0 \mu \mathrm{m})$ and higher in scan $\mathrm{E}(8.5 \mu \mathrm{m})$.

Fig. 5 analyzes the locomotion of the OPC in more detail. The trajectories of the origin of the rear process (blue arrow), the cell maximum (green arrow) and and the origin of the front process (red arrow) are superimposed on the top view of the data of the first scan in Fig. 5A. The frontal point was defined as the point of steepest slope in the direction of movement and the rear end as the point of steepest slope in the direction of retraction. The inset compares the trajectories (magnified three times; rearranged for clarity). Whereas between scans A and B as well as between scans $\mathrm{C}$ and $\mathrm{F}$ (Fig. 4) the cell moves into its heading direction it undergoes a change in shape leading to a lateral movement of the cell front (indicated by the red trajectory of the origin of the frontal process) between scans $\mathrm{B}$ and $\mathrm{C}$ (indicated by the black arrow-head in the
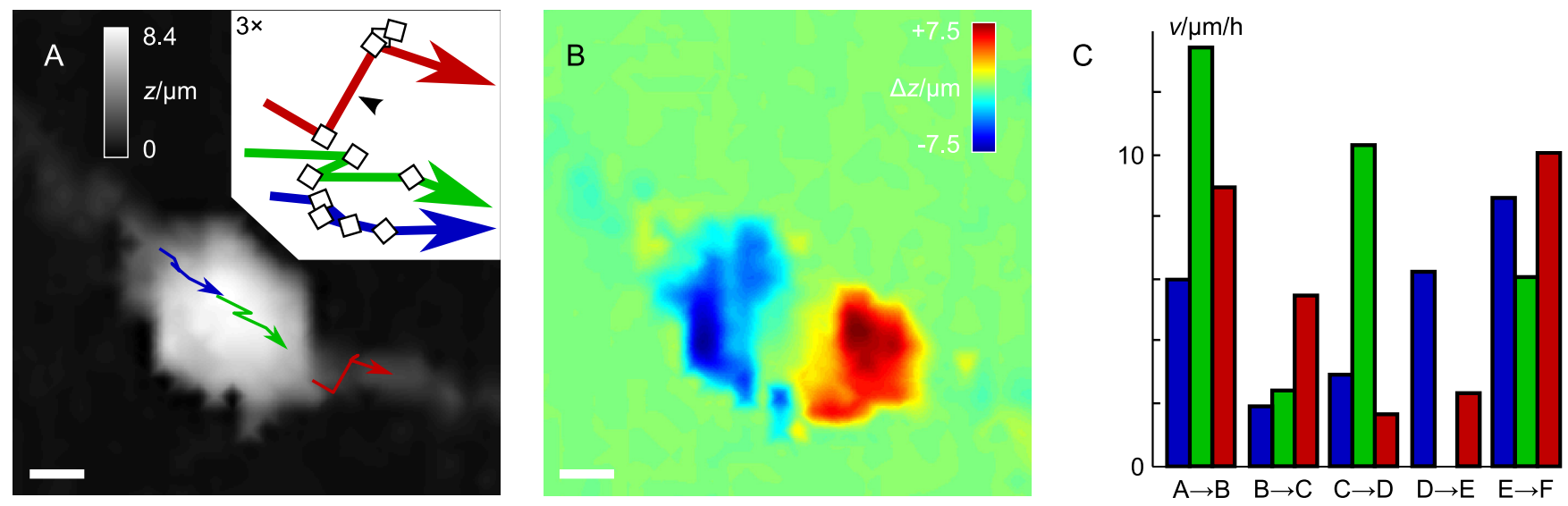

Figure 5

Migration analysis of the OPC depicted in Fig 4. (A) Trajectories of the origin of the frontal process (red), the maximum cell height (green) and the origin of the rear process (blue) superimposed on the top-view of the data of the first scan (Fig. 4 A); inset shows the magnified trajectories (rearranged for clarity). (B) Difference image between first and last scan. Lateral scale bars in (A) and (B) represent $3 \mu \mathrm{m}$. (C) Plots of the velocities of each of the three points of observation as defined in (A). 
inset). In contrast, the rear process only shows minor lateral movements as indicated by the trajectory of the corresponding point of observation (blue trajectory).

Fig. 5B shows the difference composed of the subtraction of the data of scan A from scan E visualizing the overall topographical changes in position during the time of observation. Again, red areas denote areas of increasing height and thus novel cell locations whereas blue areas represent areas of decreasing height corresponding to previous cell locations. Overall locomotion distances amount to $4.3 \mu \mathrm{m}, 5.0 \mu \mathrm{m}$ and $4.4 \mu \mathrm{m}$ for frontal, maximal and rear observation point, respectively, yielding velocities of $3.4 \mu \mathrm{m} / \mathrm{h}, 4.0 \mu \mathrm{m} / \mathrm{h}$ and $3.5 \mu \mathrm{m} / \mathrm{h}$ for the respective parts of the cell.

The single average velocities of the points of observation are plotted in Fig. 5C (colors correspond to the trajectories shown in Fig. 5A). Average velocities were calculated from the locomotion distance and the time interval between two successive scans. Between frames A and B all three points of observation moved relatively fast with a velocity of about $9 \mu \mathrm{m} / \mathrm{h}$ (front), $12 \mu \mathrm{m} / \mathrm{h}$ (maximum) and $6 \mu \mathrm{m} /$ $\mathrm{h}$ (rear). Hence, the point of maximal cell height nearly moved twice as fast as the rear part. Between scans B and $\mathrm{C}$ movement was slower. Nevertheless, the frontal point of observation moved approximately three times faster than the top of the cell and the rear part (about $6 \mu \mathrm{m} / \mathrm{h}$ compared with about $2 \mu \mathrm{m} / \mathrm{h}$ ). Subsequently, the frontal and rear section nearly maintained their position while the cell maximum moved rapidly (respective velocities from back to front: $3 \mu \mathrm{m} / \mathrm{h}, 10 \mu \mathrm{m} / \mathrm{h}, 2 \mu \mathrm{m} / \mathrm{h}$ ), followed by a distinct movement of the rear part of the cell while the highest point remained stationary. Between the last two scans all three cell parts moved rapidly yet the movements of the outer parts dominated. Most interestingly, the front end of this particular cell exhibited the largest, more exploratory movements whereas the other parts followed with smaller lateral displacements.

The determined velocities match the velocities previously determined in a detailed study of OPC migration [18] that yielded a mean migration velocity of about $10 \mu \mathrm{m} / \mathrm{h} \pm 7$ $\mu \mathrm{m} / \mathrm{h}$ for OPCs on poly-L-Lysin.

During cellular activity local concentration changes at the cell surfaces may occur which can amount to approximately $10 \%$ under conditions such as enhanced neuronal activity [19]. This would affect height detection with the SICM by $10 \%$ since the resistance depends linearly on the conductance. At the surface of isolated cells in culture the equilibration of local concentration changes is expected to be speeded by membrane movements caused by water fluxes through aquaporins as well as the large diffusion space of the bath solution.
The speed with which local concentration changes are equilibrated was estimated as follows: The conductance of the bath medium is mainly carried by $\mathrm{NaCl}$ at the concentration $c_{0}$. The diffusion coefficient of $\mathrm{NaCl}$ in water at room temperature is assumed as $D \approx 10^{-9} \mathrm{~m}^{2} / \mathrm{s}[20,21]$ and further assumed to be independent from the $\mathrm{NaCl}$ concentration. The distance between probe and sample that caused the observed resistance to increase to the stop criterion was approximated from approach curves and estimated to be about $400 \mathrm{~nm}$. Thus potential electrolyte changes exceeding $400 \mathrm{~nm}$ could disturb height detection notably. As maximal possible concentration change that could distort our measurements we assume a cube with an edge length of $l=1 \mu \mathrm{m}$ depleted of $\mathrm{NaCl}$ and located at the border of the sample surface. We define the coordinate $x=0$ as the location of the interface between the cube, that itself is located at $x>0$, and the bath, located at $x<0$, in one dimension. Diffusion into the cube is described by Fick's second law, $(\partial c / \partial t)_{x}=D \partial^{2} c / \partial x^{2}$ (equation 1), and the average concentration $\bar{c}$ inside the cube at time $t$ is given by $\bar{c}(t)=l^{-1} \int_{0}^{l} c(x, t) \mathrm{d} x$ (equation 2) where $c(x, t)$ is the concentration at location $x$ inside the cube at time $t$. Fick's second law is solved assuming the following boundary conditions: At $t=0 \mathrm{~s}$ the concentration inside the cube is $c=0 \mathrm{mM}$, outside the cube it is $c=c_{0}$ and for $t>0 \mathrm{~s}$, the concentration outside the cube is still $c=c_{0}$ for locations far away from the cube $(x \rightarrow-\infty)$. To solve the differential equation (eq. 1) we further assume $c=0 \mathrm{mM}$ for $x \rightarrow \infty$.

Inserting the solution of eq. 1 obtained by using these boundary conditions into eq. 2 yields $\bar{c}(t)=\sqrt{D t / \pi} \times c_{0} / l$. Simplifying this by approximating $\sqrt{D / \pi} \times 1 / l \approx 10 \mathrm{~s}^{1 / 2}$ (note that $\mathrm{s}^{1 / 2}$ denotes the square root of a second) results in $\bar{c}(t)=c_{0} \times 10 \mathrm{~s}^{1 / 2} \times \sqrt{t}$. This yields $\bar{c}(t=0.001 \mathrm{~s})=c_{0}$, hence, the putative concentration difference would be compensated in roughly $10 \mathrm{~ms}$.

This estimation neglects the fact that ion influxes into the cube from five directions occur (assuming the sixth direction is the probe surface) and particularly the turbulences caused by the motion of the scanning tip that most likely further enhance the speed of concentration equilibration.

Since the frame aqcuisition time was about 10 minutes for scans consisting of 900 pixels and about 20 minutes for scans consisting of 3600 pixels, on the average a pixel was detected every $500 \mathrm{~ms}$ to $600 \mathrm{~ms}$. Since this is 50 fold to 
60 fold the time we estimated for the equilibration of the maximal possible concentration difference we assumed that influences in height detection due to ionic fluxes across the cell membrane were negligible. Nevertheless, they might affect SICM measurements operating in faster scanning modes.

Our records demonstrate that SICM in floating backstep operation is a suitable tool for long term recordings of single living cells in culture. Our present observations of a neurite and the rearrangements of neural processes show that the SICM can be stably operated to allow investigations on vital cell structures for more than 8 hours. Whereas SICM not yet achieves the lateral resolution of AFM measurements a lateral step size of $500 \mathrm{~nm}$ is already sufficient to grossly locate structures like lamellipodia. Further refinements of operation mode, software and scanning tips allow more detailed and high-speed scans of selected structures [13]. However, smaller probe tips required for higher resolution imaging detect the surface at a smaller distance between probe and sample [22] and thus might cause distortions of the cell movements [15]. Most remarkably, the ability to image entire cell somata repeatedly and to determine velocities of subcellular parts of a cell provides new options for the investigation of changes in cellular shape during migration, potentially providing a tool to investigate the subcellular distribution of activity of ion- and water channels involved in cell migration $[23,24]$ combined with the corresponding subcellular cell surface changes.

Our results confirm that OPCs migrate in a saltatory manner [18] and indicate that the displacement of the nucleus, that presumably corresponds to the maximal $z$-value [3], and the movement of the cell soma boundaries occur in a distinct but concerted manner. Further investigation of migrating cells with backstep SICM may unravel the local dynamics during cell migration and thus help to complete our understanding of the mechanisms driving cell migration.

\section{Competing interests}

The authors declare that they have no competing interests.

\section{Authors' contributions}

Both authors designed the project and prepared the manuscript. PH carried out most of the SICM measurements and data analysis.

\section{Additional material}

\author{
Additional file 1 \\ Long term observation of the terminal part of a nerve cell process. A \\ movie composed of top views of the data presented in Figure 1. \\ Click here for file \\ [http://www.biomedcentral.com/content/supplementary/1477- \\ 3155-7-7-S1.MPG]
}

\section{Additional file 2}

Long term observation of two neural cells. A movie composed of top views of the data presented in Figure 3.

Click here for file

[http://www.biomedcentral.com/content/supplementary/1477-

3155-7-7-S2.MPG]

\section{Additional file 3}

Observation of a migrating oligendrocyte precursor cell. A movie composed of the data presented in Figure 4.

Click here for file

[http://www.biomedcentral.com/content/supplementary/1477-

3155-7-7-S3.MPG]

\section{Acknowledgements}

Part of the work was supported by a fellowship to PH from the Allgemeines Graduiertenkolleg der Ruhr-Universität Bochum. We thank Romy Marx and Vanessa Niederkinkhaus for help with the cell culture, Maren D. Lange for performing some SICM measurements, Stefan A. Mann for helpful discussions, Rolf Heumann, Jan Meijer and the RUBION-team for continuous support.

\section{References}

I. Binnig G, Quate CF, Gerber C: Atomic Force Microscope. Phys Rev Lett 1986, 56:930-933.

2. Ohnesorge FM, Horber JK, Haberle W, Czerny CP, Smith DP, Binnig G: AFM review study on pox viruses and living cells. Biophys J 1997, 73(4):2183-94.

3. Yunxu S, Danying L, Yanfang R, Dong H, Wanyun M: Three-dimensional structural changes in living hippocampal neurons imaged using magnetic AC mode atomic force microscopy. J Electron Microsc (Tokyo) 2006, 55(3): 165-72.

4. Xiong Y, Lee AC, Suter DM, Lee GU: Topography and nanomechanics of live neuronal growth cones analyzed by atomic force microscopy. Biophys J 2009, 96(I 2):5060-72.

5. Colton RJ, Baselt DR, Dufrene YF, Green JB, Lee GU: Scanning probe microscopy. Curr Opin Chem Biol I997, I(3):370-7.

6. Hansma P, Drake B, Marti O, Gould S, Prater C: The scanning ionconductance microscope. Science 1989, 243(489I):64I-3.

7. Korchev Y, Bashford C, Milovanovic M, Vodyanoy I, Lab M: Scanning ion conductance microscopy of living cells. Biophys J 1997, 73(2):653-8.

8. Gorelik J, Shevchuk AI, Frolenkov GI, Diakonov IA, Lab MJ, Kros CJ, Richardson GP, Vodyanoy I, Edwards CRW, Klenerman D, Korchev YE: Dynamic assembly of surface structures in living cells. Proc Natl Acad Sci USA 2003, $100(10): 5819-22$.

9. Gorelik J, Zhang Y, Shevchuk Al, Frolenkov GI, Sánchez D, Lab MJ, Vodyanoy I, Edwards CRW, Klenerman D, Korchev YE: The use of scanning ion conductance microscopy to image A6 cells. Mol Cell Endocrinol 2004, 217(I-2):10I-8.

10. Mann SA, Hoffmann G, Hengstenberg A, Schuhmann W, Dietzel ID: Pulse-mode scanning ion conductance microscopy-a method to investigate cultured hippocampal cells. J Neurosci Methods 2002, II6(2): II3-7. 
II. Happel P, Hoffmann G, Mann S, Dietzel ID: Monitoring cell movements and volume changes with pulse-mode scanning ion conductance microscopy. J Microsc 2003, 2 I 2(Pt 2): 144-51.

12. Happel P, Wehner F, Dietzel ID: Scanning ion conductance microscopy$a$ tool to investigate electrolyte-nonconductor interfaces 2007, 2:968-975 [http://www.formatex.org/microscopy3/pdf/pp968-975.pdf]. FORMATEX, Modern Research and Educational Topics in Microscopy

13. Novak P, Li C, Shevchuk Al, Stepanyan R, Caldwell M, Hughes S, Smart TG, Gorelik J, Ostanin VP, Lab MJ, Moss GW, Frolenkov GI, Klenerman D, Korchev YE: Nanoscale live-cell imaging using hopping probe ion conductance microscopy. Nat Methods 2009, 6(4):279-8I.

14. Rheinlaender J, Schaeffer TE: Image formation, resolution, and height measurement in scanning ion conductance microscopy. J Appl Phys 2009, I 05(9):.

15. Pellegrino M, Orsini P, De Gregorio F: Use of scanning ion conductance microscopy to guide and redirect neuronal growth cones. Neurosci Res 2009, 64(3):290-6.

16. Niederkinkhaus V, Marx R, Hoffmann G, Dietzel ID: Thyroid hormone (T3)-induced up-regulation of voltage-activated sodium current in cultured postnatal hippocampal neurons requires secretion of soluble factors from glial cells. Mol Endocrinol 2009, 23(9): 1494-504

17. Mann SA, Versmold B, Marx R, Stahlhofen S, Dietzel ID, Heumann R, Berger R: Corticosteroids reverse cytokine-induced block of survival and differentiation of oligodendrocyte progenitor cells from rats. J Neuroinflammation 2008, 5:39.

18. Schmidt C, Ohlemeyer C, Labrakakis C, Walter T, Kettenmann H, Schnitzer ]: Analysis of motile oligodendrocyte precursor cells in vitro and in brain slices. Glia 1997, 20(4):284-98.

19. Dietzel I, Heinemann U, Hofmeier G, Lux H: Stimulus-induced changes in extracellular $\mathrm{Na}^{+}$and $\mathrm{Cl}$-concentration in relation to changes in the size of the extracellular space. Exp Brain Res 1982, 46:73-84.

20. Harned $\mathrm{H}$, Hildreth $\mathrm{C}$ : The Differential Diffusion Coefficients of Lithium and Sodium Chorides in Dilute Aqueous Solution at 25-Degrees. Journal of the American Chemical Society 195I, 73(2):650-652.

21. Rard J, Miller D: Mutual Diffusion-Coefficients of $\mathbf{N a C l}-\mathbf{H} 2 \mathrm{O}$ and $\mathrm{CaCl}$ - $\mathrm{H} 2 \mathrm{O}$ at 25-Degrees-C from Rayleigh Interferometry. Journal of Solution Chemistry 1979, 8(1 0):701-716.

22. Nitz H, Kamp J, Fuchs H: A Combined Scanning lon-Conductance and Shear-Force Microscope. Probe microsc 1998, I: $187-200$

23. Schwab A, Nechyporuk-Zloy V, Fabian A, Stock C: Cells move when ions and water flow. Pflugers Arch 2007, 453(4):42I-32.

24. Papadopoulos MC, Saadoun S, Verkman AS: Aquaporins and cell migration. Pflugers Arch 2008, 456(4):693-700.
Publish with Bio Med Central and every scientist can read your work free of charge

"BioMed Central will be the most significant development for disseminating the results of biomedical research in our lifetime. "

Sir Paul Nurse, Cancer Research UK

Your research papers will be:

- available free of charge to the entire biomedical community

- peer reviewed and published immediately upon acceptance

- cited in PubMed and archived on PubMed Central

- yours - you keep the copyright
BioMedcentral 